\title{
PERLINDUNGAN HAK CIPTA BAGI PENGUNGGAH VIDEO YOUTUBE YANG DIGUNAKAN OLEH STASIUN TELEVISI
}

\author{
M.FADEL ZULKARNAIN \\ 155100044,785567967 \\ Fakultas Komputer \\ fadelzulkarnain.student@umitra.ac.id
}

\begin{abstract}
Video adalah merupakan salah satu karya cipta yang dilindungi oleh hak cipta oleh Undang-Undang, yaitu adalah Undang-Undang Nomor 28 Tahun 2014 tentang Hak Cipta. Namun dalam prakteknya sering sekali masih terjadi pelanggaran-pelanggaran terhadap karya hak cipta video yang merupakan hak milik dari seorang pencipta, salah satu pelanggaran nya adalah pada saat video tersebut diunggah ke dalam suatu situs internet yaitu Youtube. dan video tersebut di tayangkan di televisi tanpa izin dari pencipta video. Permasalahan yang timbul sekarang adalah bagaimana pengaturan hubungan hukum antara youtube dengan stasiun televisi, bagaimana tanggung jawab stasiun televisi terhadap youtube atas video yang diunggah di televisi, bagaimana perlindungan hak cipta menurut undang-undang nomor 28 tahun 2014 tentang hak cipta terhadap pencipta video yang diunggah di youtube yang di tayangkan di televisi.

Penelitian ini menggunakan metode penelitian hukum normatif yang bersifat deskriptif kualitatif, yakni pendekatan dari sudut pandang menurut ketentuan hukum dan ketentuan peraturan perundang-undangan yang berlaku.

Dari hasil penelitian ini bahwa situs youtube sudah memberikan syarat dan ketentuan bagi pengunggah video, dan dengan adanya aturan tersebut maka akan timbul hubungan hukum dan akan melahirkan hak dan kewajiban bagi pencipta video maupun kepada stasiun televisi sebagai pihak ketiga yang mengambil video dari youtube yang ditayangkan di stasiun televisi dengan diambilnya video tersebut maka pihak stasiun televisi haruslah mendapatkan izin terlebih dahulu kepada pencipta video tersebut dan mencantumkan courtesy of youtube (bersumber dari youtube) dan nama pencipta video. Adapun dari keuntungan yag didapat oleh stasiun televisi dengan menyiarkan video tersebut secara komersial stasiun televisi juga harus memberikan sebagian keuntungan (royalti) terhadap pencipta video.
\end{abstract}

Kata Kunci : Hak Cipta, Video, Perlindungan Hukum 


\section{A. INTRODUCTION}

Dalam masa pembangunan nasional yang ditandai dengan terjadinya globalisasi di segala bidang, batasbatas suatu negara akan menjadi kabur dan keterkaitan antara ekonomi nasional dengan perekonomian internasional akan semakin erat. Globalisasi perekenomian di satu pihak akan membuka peluang pasar produk dalam negeri ke pasar internasional secara kompetitif, sebaliknya juga membuka peluang masuknya produk-produk global ke pasar domestik. Situasi perkembangan perekonomian global akan segera menimbulkan dampak yang nyata atas perekenomian nasional, termasuk sektor kekayaan intelektual.

Indonesia yang memiliki keanekaragaman etnik/suku bangsa dan budaya serta kekayaan di bidang seni dan sastra yang selalu berkembangan, memerlukan perlindungan hak cipta terhadap kekayaan intelektual.yang lahir dari keanekaragaman tersebut. Dalam perkembangan di era globalisasi khususnya di bidang perdangan, industri, dan investasi yang telah sedemikian pesat, sehingga memerlukan peningkatan perlindungan bagi pencipta. dan pemilik hak terkait dengan tetap memperhatikan kepentingan masyarakat luas maupun luar negeri. Globalisasi adalah bentuk kolonialisme imperialisme baru dibidang ekonomi. Pendapat lain memandang globalisasi sebagai sebuah tantangan masa depan. Tantangan yang mesti dijawab untuk memasuki tata dunia baru. "Bahwa globalisasi tidaklah terjadi di dunia bisnis semata, tetapi juga di dunia hukum, sosial dan budaya. Dalam aspek ini globalisasi perlu diantisipasi karena dapat membawa dampak yang besar terhadap peri kehidupan manusia secara keseluruhan. Salah satu perkembangan yang menonjol dan memperoleh perhatian seksama dalam masa sepuluh tahun terakhir dan kecenderungan yang masih berlangsung di masa yang akan datang adalah meluasnya globalisasi baik dibidang sosial, ekonomi, budaya maupun bidang-bidang kehidupan lainnya. Di bidang perdagangan, terutama karena perkembangan teknologi informasi dan transformasi telah menjadikan kegiatan di sektor ini meningkat secara pesat dan bahkan telah menempatkan dunia sebagai pasar tunggal bersama. Globalisasi bukan hanya dalam bidang perdagangan saja, tetapi berupa hasil penemuan, diantaranya Hak Kekayaan Intelektual dapat diartikan sebagai hak atas kepemilikan terhadap karya-karya yang timbul atau lahir karena adanya kemampuan intelektualitas manusia dalam bidang ilmu pengetahuan dan teknologi. Setelah dunia dikejutkan dengan media-media social network yang meningkatkan popularitas penggunaan intenet, pada tahun 2005 sebuah situs yang khusus berisi videovideo amatir hasil unggahan di internet menjadi gebrakan inovasi di bidang perputaran informasi. Situs bernama Youtube ini pada awalnya ditujukan sebagai wadah tempat video-sharing atau berbagi video berisi rekaman atau suatu peristiwa yang sifatnya terbuka kepada publik. Seiring dengan berjalannya waktu pengguna Youtube memanfaatkan situs ini tidak hanya 
sebagai ajang untuk saling bertukar informasi, tetapi juga sebagai sarana pengekspresian diri, hiburan, penyebaran ide, dan edukasi hingga politik.

Manusia pada fitrahnya memiliki kemampuan untuk mencipta, berkreasi dan menghasilkan sesuatu dari hasil daya pikir dan kemampuannya. Setiap orang dapat menghasilkan karya yang berbeda, karya-karya tersebut bernilai artistik, dan bermanfaat bagi manusia lainnya. Oleh karena karya hasil daya pikir dan kemampuan ini kerap digunakan dan dimanfaatkan secara bersama sama dalam masyarakat, maka pengaturannya secara hukum, agar terciptanya kehidupan yang harmoni antar sesama manusia. Hal ini disebut Kekayaan Intelektual, dan terdapat Hukum Kekayaan Intelektual sebagai norma pengaturannya. Kekayaan intelektual adalah kekayaan atas segala hasil produksi kecerdasan daya pikir seperti teknologi, pengetahuan, seni, sastra, gubahan lagu, karya tulis, karikatur dan seterusnya, sedangkan Hak Kekayaan Intelektual (HKI) adalah hak-hak (wewenang/kekuasaan) untuk berbuat sesuatu atas kekayaan intelektual tersebut, yang diatur dalam normanorma atau hukum-hukum yang berlaku

\section{B. CONTENT}

Hak kekayaan Intelektual (HKI) atau istilah dalam bahasa Inggris Intellectual Property Rights adalah salah satu hak yang timbul atau lahir karena kemampuan intelektual manusia. Istilah intellectual Property Rights merupakan isitilah umum dalam bahasa inggris yang di Indonesia diterjemahkan dalam beberapa istilah. Di Indonesia penggunaan istilah yang dianggap padanan kata intellectual property rights di dalam perkembangan tata hukumnya maupun yang digunakan oleh beberapa penulisan pada awalnya digunakan istilah Hak Milik Kekayaan Intellektual (HMKI) , kemudian menjadi Hak atas Kekayaan Intelektual (HaKI) dan istilah terakhir yang digunakan adalah Hak Kekayaan Intelektual (HKI). Istilah hak milik kekayaan intelktual berasal dari kata Intellectuale eigendomrechts (Bahasa Belanda) dalam sistem Eropa Kontinental. Istilah hak milik kekayaan intelktual dari telah lama digunakan terutama oleh beberapa penulis seperti Sudargo Gautama,C.S.T.Kansil,Muhammad Djumhana, dalam bukunya terbitan tahun 1990-an banyak menggunakan istilah Hak Milik Intelektual (HMI) HKI adalah suatu hak eksklusif yang berada dalam ruang lingkup kehidupan teknologi, ilmu pengetahuan, ataupun seni dan sastra. Kepemilikannya bukan terhadap barangnya melainkan terhadap hasil kemampuan dan kreativitas intelektual manusianya, yaitu diantaranya berupa ide dan gagasan . Hal yang terpenting dari setiap bagian hak milik intelektual ini adalah adanya uatu hasil ciptaan tertentu. Ciptaan ini mungkin dalam bidang kesenian, tetapi mungkin juga di dalam bidang industri atau pengetahuan. Mungkin pula suatu kombinas dalam ketiga bidang tersebut yang masing-masing punya istilah tersebut. 
Hak kekayaan intelektual bersifat eksklusif dan mutlak, artinya bahwa hak tersebut dapat dipertahankan terhadap siapapun dan yang mempunyai hak tersebut. dapat menuntut terhadap pelanggaran yang dilakukan oleh siapapun. Pemegang hak atas kekayaan intelektual mempunyai hak monopoli, yaitu hak yang dapat dipergunakan dengan melarang siapapun tanpa persetujuannya membuat ciptaan/penemuannya ataupun menggunakannya.

Kemampuan intelektual manusia yang berupa daya cipta, rasa dan karsanya menghasilkan karyakarya di bidang ilmu pengetahuan, seni, dan teknologi. Karya-karya intelektual dilahirkan dengan pengorbanan waktu bahkan biaya dan melalui pengorbanan ini menjadikan karya yang dihasilkan mempunyai nilai ekonomi yang melekat sebagai konsekuensi menjadi kekayaan (property), bilamana melalui karyakarya tersebut dapat diperoleh manfaat ekonomi yang nantinya bisa dinikmati. HKI baru muncul bilamana hasil intelektual manusia tesebut telah membentuk sesuatu yang dapat dilihat, didengar, dibaca, maupun digunakan secara praktis. Disamping itu kreativitas intelektual juga harus orisinil atau asli (original) dan baru sama sekli ataupun memperbarui dari kreativitas sebelumnya

.Salah satu kenyataan yang mencerminkan bahwa masalah Hak Kekayaan Intelektual dalam hal ini hak cipta dapat terus berkembang sesuai dengan ilmu pengetahuan dan teknologi misalnya saja perihal program televisi yang biasa kita tonton bersama keluarga di rumah. Stasiun televisi menayangkan programprogram yang berisi informasi ringkas dengan cuplikan video dari Youtube. Sebagian gambarnya diambil dari situs web video sharing yang dapat memuat,menonton,dan berbagi video klip.

.Salah mengunggahnya di YouTube
mencerminkan bahwa masalah Hak Kekayaan Intelektual dalam hal ini hak cipta dapat terus berkembang sesuai dengan ilmu pengetahuan dan teknologi misalnya saja perihal program televisi yang biasa kita tonton bersama keluarga di rumah. Stasiun televisi menayangkan programprogram yang berisi informasi ringkas dengan cuplikan video dari Youtube.

Sebagian gambarnya diambil dari situs web video sharing yang dapat memuat,menonton,dan berbagi video klip.

Program televisi yang menggunakan gambar dari Youtube ini biasanya bersifat informasi. On The Spot salah satu program milik stasiun televisi Trans 7 misalnya menayangkan informasi seputar 7 gambar pilihan berdasarkan tema tertentu. Sebagai contoh, tentang tujuh tempat terdalam di dunia. Meski informasinya sederhana dan ringkas ternyata acara ini mendapatkan rating cukup bagus. Apresiasi penonton yang cukup bagus ini membuat stasiun televisi lain mulai membuat program serupa. Salah satunya adalah PT Rajawali Citra televisi Indonesia (RCTI). Mulai senin 7 September 2011 
lalu, RCTI membuat program bernama Top5. Sebelumnya ada PT Cakrawala Andalas Televisi atau yang biasa kita kenal ANTV yang membuat program serupa bernama wooow. Di lain pihak Celebes TV juga menampilkan video Youtube dalam program acaranya, tidak hanya program televisi menyangkut penayangan informasi Celebes TV juga menayangkan program m televisi musik, video klip, yang berasal dari hasil dari unduhan website utuh. Padahal seharusnya stasiun televisi ini harus membeli terlebih dahulu video tersebut dari perusahaan yang membuat video klip tersebut.

Para pemilik stasiun televisi ini memang merasa sangat dimudahkan dengan adanya fasilitas video Youtube. Mereka tinggal mengambil video dari situs gratis itu dan mendapatkan untung dari program yang ditampilkan. Membuat program televisi yang menggunakan konten Youtube memang cukup menguntungkan. Hanya saja menggunakan video yang di-upload orang lain tentu cukup riskan. Untungnya sampai saat ini belum ada pengunggah yang merasakan dirugikan karena program televisi ini. Meski begitu, Komisi Penyiaran Indonesia (KPI) mulai mengkhawatirkan masalah ini. Youtube hanya mempunyai

mechanical rights (hak untuk memutar alias play out). Jadi mereka tidak memilik hak atas karya. Hak pemilik hak karya ada pada si pengunggah. Karena itu seharusnya courtesy yang dicantumkan dalam tayangan merupakan nama pemilik karya. Nama pemilik karya dari video tersebut merupakan orang yang mengunggah video tersebut ke dalam situs Youtube dan nama pemilik karya tersebut tidak boleh dihilangkan begitu saja, karena kita ketahui bersama di dalam hak cipta dikenal dengan adanya hak moral. Hak moral sendiri bararti hak yang melekat pada diri pencipta atau pelaku yang tidak dapat dihilangkan atau dihapus tanpa alasan apapun, walaupun Hak cipta atau hak terkait sudah dialihkan. Perlindungan Hak Cipta berdasarkan Undang-Undang Nomor 28 Tahun 2014 tentang Hak Cipta (UUHC) tidak diberikan kepada ide atau gagasan karena karya cipta harus memiliki bentuk yang khas, bersifat pribadi, dan menunjukkan keaslian sebagai ciptaan yang lahir berdasarkan kemampuan, kreativitas, atau keahlian sehingga ciptaan itu dapat dilihat, dibaca, atau didengar.

Selain hak moral dalam hak cipta juga dikenal adanya hak ekonomi. Hak Ekonomi sendiri diartikan hak untuk mendapatkan manfaat ekonomi atas ciptaan serta produk hak terkait. Jadi, sebenarnya pencipta bisa saja mendapatkan keuntungan ekonomi dari stasiun televisi di mana stasiun televisi tersebut

\section{CONCLUSION}

Dengan adanya hubungan hukum antara pihak stasiun televisi dengan youtube dan pencipta video maka akan melahirkan hak dan kewajiban bagi kedua belah pihak agar mencapai tujuan kedua belah pihak tersebut, yang mana 
hubungan hukum tersebut akan melahirkan tanggung jawab kepada pihak yang melanggar atau yang akan melanggar hukum dan dengan adanya hubungan hukum maka perlindungan hukum akan menjadi pasti. Walaupun pihak stasiun televisi tidak memiliki hubungan hukum dengan youtube Tetapi pihak stasiun tv haruslah memenuhi syarat ketentuan yang ada pada youtube, oleh karena itu maka pencipta video youtube akan merasa terlindungi karyanya, yang mana setiap karya yang telah menjadi karya yang nyata harus mempunyai suatu perlindungan agar karya tersebut dapat dijaga dan diketahui pemilik asli karya tersebut siapa. baik itu karya video, lagu, musik, sinematografi, dan lain-lain Undang-undang Hak Cipta

Nomor 28 Tahun 2014 dengan hanya menyantumkan bersumber dari mana tidak lah cukup, tetapi harus juga memberikan keuntungan kepada pencipta video.

\section{DISCUSSION}

Manusia pada fitrahnya memiliki kemampuan untuk mencipta, berkreasi dan menghasilkan sesuatu dari hasil daya pikir dan kemampuannya. Setiap orang dapat menghasilkan karya yang berbeda, karya-karya tersebut bernilai artistik, dan bermanfaat bagi manusia lainnya. Oleh karena karya hasil daya pikir dan kemampuan ini kerap digunakan dan dimanfaatkan secara bersama sama dalam masyarakat, maka pengaturannya secara hukum, agar terciptanya kehidupan yang harmoni antar sesama manusia. Hal ini disebut Kekayaan Intelektual, dan terdapat Hukum Kekayaan Intelektual sebagai norma pengaturannya. Kekayaan intelektual adalah kekayaan atas segala hasil produksi kecerdasan daya pikir seperti teknologi, pengetahuan, seni, sastra, gubahan lagu, karya tulis, karikatur dan seterusnya, sedangkan Hak Kekayaan Intelektual (HKI) adalah hak-hak (wewenang/kekuasaan) untuk berbuat sesuatu atas kekayaan intelektual tersebut, yang diatur dalam normanorma atau hukum-hukum yang berlaku. Kemampuan intelektual manusia yang berupa daya cipta, rasa dan karsanya menghasilkan karyakarya di bidang ilmu pengetahuan, seni, dan teknologi. Karya-karya intelektual dilahirkan dengan pengorbanan waktu bahkan biaya dan melalui pengorbanan ini menjadikan karya yang dihasilkan mempunyai nilai ekonomi yang melekat sebagai konsekuensi menjadi kekayaan (property), bilamana melalui karyakarya tersebut dapat diperoleh manfaat ekonomi yang nantinya bisa dinikmati. HKI baru muncul bilamana hasil intelektual manusia tesebut telah membentuk sesuatu yang dapat dilihat, didengar, dibaca, maupun digunakan secara praktis. Disamping itu kreativitas intelektual juga harus orisinil atau asli (original) dan baru sama sekli ataupun memperbarui dari kreativitas sebelumnya 


\section{E. REFERENCE}

[1] O. M. Febriani and A. S. Putra, "Sistem Informasi Monitoring Inventori Barang Pada Balai Riset Standardisasi Industri Bandar Lampung," J. Inform., vol. 13, no. 1, pp. 90-98, 2014.

[2] A. S. Putra, "Paperplain: Execution Fundamental Create Application With Borland Delphi 7.0 University Of Mitra Indonesia," 2018.

[3] A. S. Putra, "2018 Artikel Struktur Data, Audit Dan Jaringan Komputer," 2018.

[4] A. S. Putra, "ALIAS MANAGER USED IN DATABASE DESKTOP STUDI CASE DB DEMOS."

[5] A. S. Putra, "COMPREHENSIVE SET OF PROFESSIONAL FOR DISTRIBUTE COMPUTING."

[6] A. S. Putra, "DATA ORIENTED RECOGNITION IN BORLAND DELPHI 7.0."

[7] A. S. Putra, "EMBARCADERO DELPHI XE 2 IN GPUPOWERED FIREMONKEY APPLICATION."

[8] A. S. Putra, "HAK ATAS KEKAYAAN INTELEKTUAL DALAM DUNIA TEKNOLOGY BERBASIS REVOLUSI INDUSTRI 4.0."

[9] A. S. Putra, "IMPLEMENTASI PERATURAN PERUNDANGAN UU. NO 31 TAHUN 2000 TENTANG DESAIN INDUSTRI BERBASIS INFORMATION TECHNOLOGY."

[10] A

S. Putra,
"IMPLEMENTATION OF PARADOX DBASE."

A. S. Putra, "IMPLEMENTATION OF TRADE SECRET CASE STUDY SAMSUNG MOBILE PHONE."

[12] A. S. Putra, "IMPLEMENTATION

PATENT FOR APPLICATION WEB BASED CASE STUDI WWW. PUBLIKLAMPUNG. COM."

[13] Putra "IMPLEMENTATION SYSTEM FIRST TO INVENT IN DIGITALLY INDUSTRY."

[14] A. S. Putra, "MANUAL REPORT \& INTEGRATED DEVELOPMENT

ENVIRONMENT BORLAND DELPHI 7.0."

[15] A. S. Putra, "PATENT AS RELEVAN SUPPORT RESEARCH."

[16] A. S. Putra, "PATENT FOR RESEARCH STUDY CASE OF APPLE. Inc."

[17] A. S. Putra, "PATENT PROTECTION FOR APPLICATION INVENT."

[18] A. S. Putra, "QUICK REPORT IN PROPERTY PROGRAMMING."

[19] A. S. Putra, "REVIEW CIRCUIT LAYOUT COMPONENT

REQUIREMENT ON ASUS NOTEBOOK."

[20] A. S. Putra, "REVIEW TRADEMARK PATENT FOR INDUSTRIAL TECHNOLOGY BASED 4.0."

[21] A. S. Putra, "TOOLBAR COMPONENT PALLETTE IN 
OBJECT

ORIENTED

PROGRAMMING."

[22] A. S. Putra, "WORKING DIRECTORY SET FOR PARADOX 7."

[23] A. S. Putra, "ZQUERY CONNECTION IMPLEMENTED

PROGRAMMING

STUDI CASE PT. BANK BCA Tbk."

[24] A. S. Putra, D. R. Aryanti, and I. Hartati, "Metode SAW (Simple Additive Weighting) sebagai Sistem Pendukung Keputusan Guru Berprestasi (Studi Kasus: SMK Global Surya)," in Prosiding Seminar Nasional Darmajaya, 2018, vol. 1, no. 1, pp. 85-97.

[25] A. S. Putra and O. M. Febriani, "Knowledge Management Online Application in PDAM Lampung Province," in Prosiding International conference on Information Technology and Business (ICITB), 2018, pp. 181-187.

[26] A. S. Putra, O. M. Febriani, and B. Bachry, "Implementasi Genetic Fuzzy System Untuk Mengidentifikasi Hasil Curian Kendaraan Bermotor Di Polda Lampung," SIMADA (Jurnal Sist. Inf. dan Manaj. Basis Data), vol. 1, no. 1, pp. 21-30, 2018.

[27] A. S. Putra, H. Sukri, and K. Zuhri, "Sistem Monitoring Realtime Jaringan Irigasi Desa (JIDES) Dengan Konsep Jaringan Sensor Nirkabel," IJEIS (Indonesian J. Electron. Instrum. Syst., vol. 8, no. 2, pp. 221-232.

[28] D. P. Sari, O. M. Febriani, and
A. S. Putra, "Perancangan Sistem Informasi SDM Berprestasi pada SD Global Surya," in Prosiding Seminar Nasional Darmajaya, 2018, vol. 1, no. 1, pp. 289-294. 